\title{
INTELLECTUAL PROPERTY (IP) FOR FUTURE ENGINEERS
}

\author{
Dumitru Olariu and Michel Loiselle \\ Canadian Intellectual Property Office (CIPO) \\ Michel.Loiselle@ic.gc.ca
}

\section{Extended Abstract}

\section{THE CANADIAN INTELLECTUAL PROPERTY OFFICE (CIPO)}

The Canadian Intellectual Property Office (CIPO) is an agency of Industry Canada responsible for the administration and processing of the greater part of intellectual property (IP) in Canada. For example, during the last fiscal year, CIPO processed approximately 100,000 patents, trade-marks, copyrights and industrial designs applications.

CIPO also plays a key role in supporting Canada's innovation performance by delivering quality and timely intellectual property rights within a modern and competitive system. CIPO strives to increase Canada's opportunities for innovation by promoting and disseminating IP rights and information to Canadian entrepreneurs, researchers and post-secondary students.

In connection with the CEEA/ACEG Conference goals to enhance the competence of graduates from Canadian engineering schools through continuous improvement in engineering education and design education, CIPO has prepared a presentation to delegates on the subject of IP and the use of IP Case Studies as a means to raise the awareness of IP amongst engineering students.

During this presentation, participants will leave with a better understanding of IP and will have the opportunity to exchange on the subject; as well as understand which teaching tools are available to assist engineering faculty in introducing IP in their classrooms.

\section{THE GAP}

A recent national review by CIPO indicated that postsecondary institutions have a low awareness of the competitive advantage an intellectual property strategy can provide. One of the key findings of the study was that IP is not widely taught across Canada, leaving budding innovators to learn about IP the hard way, that is, in the marketplace.
The same holds true for researchers and graduates from a range of disciplines, such as business, engineering, sciences, industrial design.

The rate of IP awareness is also low amongst Canadian businesses. Only $22 \%$ of businesses actively involved in R\&D make use of the free IP databases on the web and $10 \%$ make use of commercial databases. (Source: CIPO surveys in 2006 and 2008.)

CIPO decided to target the university sector and raise the level of IP awareness in Canadian colleges and universities. Engineering students were targeted specifically because they are the innovators of tomorrow.

In connection with CIPO's role to increase opportunities for innovation and help foster a prosperous marketplace, CIPO encourages engineers to learn more about IP and to launch their new ideas beyond the lab into the marketplace, ultimately changing Canada's economy.

\section{WHY DOES IP MATTER?}

IP rights can turn ideas into valuable assets:

- Through licensing, sale or commercialization;

- By increasing the value for investors or financing institutions; and

- By enhancing corporate identity through trademark and/or branding strategies.

Strategic use of IP information can help:

- Identify trends in technologies;

- Avoid duplication in research, development and marketing;

- $\quad$ Find solutions to problems; and

- Identify partners.

Students, researchers and professors create, innovate, and conduct important research, which may result in commercially valuable IP. 


\section{IP CASE STUDIES: A TEACHING TOOL FOR POST-SECONDARY INSTITUTIONS}

To help improve the level of IP awareness, CIPO has developed a number of IP Case Studies designed and accompanying teaching guides as teaching tools for engineering, science, business and industrial design students in post-secondary institutions across Canada.

The IP Case Studies are teaching tools that demonstrate the strategic value of IP to college and university students. Since the launch of the IP Case Studies project in September 2009, CIPO has successfully delivered 150 sessions at more than 80 post-secondary institutions across Canada.

The evaluation of the IP Case Studies initiative carries promise in raising the level of awareness in postsecondary institutions across Canada:

- Most students (88\%) recognize the value of IP after participating in an IP Case Study session.

- Most students (72\%) think knowledge of IP would be useful for them in their careers.

- Nearly all professor respondents (94\%) thought the case study was effective at raising awareness about IP.

The IP Case Studies aim to:

- Give students a baseline knowledge of IP;

- Foster classroom discussion of the use of IP in the inventive process; and

- Explain how IP can be a competitive advantage in business.
These teaching tools are designed to reflect realistic career situations for students, particularly those studying engineering, science, business, and industrial design. Using a 60 to 90 minute in-class discussion format, each case study can be easily integrated into an existing course.

The case study package includes the case study text, a discussion leader's guide and an outline for classroom discussions. Upon request and when available, a trained Discussion Leader is available to support the delivery of the materials at no cost to the institution.

The IP Case Studies ultimately demonstrate that:

1. Intellectual property is a valuable asset, and when used strategically, it can increase competitiveness and allow a business venture to reap numerous benefits.

2. Knowing more about IP can benefit engineering students in the area of innovation, finding engineering solutions in the free IP databases, protecting their own innovations and creations and learning how to benefit from IP protection.

3. The real value of IP resides in the capacity to exploit it. An innovative business venture will make effective use of IP to market itself, sell more products and services, and leverage its resources and skills in order to gain competitive advantage in the marketplace.

Conference participants can find out more about the role of IP in education by consulting the CIPO website at www.cipo.gc.ca. IP Case Studies can be reserved for the upcoming 2012 fall session by contacting CIPO and by consulting the IP resources available on-line on CIPO's website. 